\title{
Tolerance: the forgotten child of plant resistance
}

\author{
Robert K Peterson ${ }^{\text {Corresp., }}{ }^{1}$ ， Andrea C Varella ${ }^{2}$, Leon G Higley ${ }^{3}$ \\ 1 Department of Land Resources and Environmental Sciences, Montana State University, Bozeman, Montana, United States \\ 2 \\ 3 School of Natural Resources, University of Nebraska - Lincoln, Lincoln, Nebraska, United States \\ Corresponding Author: Robert K Peterson \\ Email address: bpeterson@montana.edu
}

Plant resistance against insect herbivory has greatly focused on antibiosis, whereby the plant has a deleterious effect on the herbivore, and antixenosis, whereby the plant is able to direct the herbivore away from it. Although these two types of resistance may reduce injury and yield loss, they can produce selection pressures on insect herbivores that lead to resistance. Tolerance, on the other hand, is a more sustainable pest management strategy because it involves only a plant response and therefore does not cause evolution of resistance in target pest populations. Despite its attractive attributes, tolerance has been poorly studied and understood. In this critical, interpretive review, we discuss tolerance to insect herbivory and the biological and socioeconomic factors that have limited its use in plant resistance and integrated pest management. First, tolerance is difficult to identify, and the mechanisms conferring it are poorly understood. Second, the genetics of tolerance are mostly unknown. Third, several obstacles hinder the establishment of high-throughput phenotyping methods for large-scale screening of tolerance. Fourth, tolerance has received little attention from entomologists because, for most, their primary interest, research training, and funding opportunities are in mechanisms which affect pest biology, not plant biology. Fifth, the efforts of plant resistance are directed at controlling pest populations rather than managing plant stress. We conclude this paper by discussing future research and development activities. 
1

2

3

4 1. Department of Land Resources and Environmental Sciences, Montana State Univ., Bozeman,

$5 \quad$ MT 59717

6 2. Department of Plant Sciences and Plant Pathology, Montana State Univ., Bozeman, MT 59717

7 3. School of Natural Resources, University of Nebraska-Lincoln, Lincoln, NE 68583

8

$9 *^{*}$ Corresponding author: Robert K. D. Peterson, Department of Land Resources and

10 Environmental Sciences, Montana State University, Bozeman, Montana, 59717-3120, 406-994-

11 7927; bpeterson@montana.edu. 


\section{Abstract}

13 Plant resistance against insect herbivory has greatly focused on antibiosis, whereby the plant has

14 a deleterious effect on the herbivore, and antixenosis, whereby the plant is able to direct the

15 herbivore away from it. Although these two types of resistance may reduce injury and yield loss, they produce selection pressures on insect herbivores that lead to herbivore resistance to the plant

17 resistance type. Tolerance, on the other hand, is a more sustainable pest management strategy

18 because it involves only a plant response and therefore does not cause evolution of resistance in

19 target pest populations. Despite its attractive attributes, tolerance has been poorly studied and understood. In this critical, interpretive review, we discuss tolerance to insect herbivory and the biological and socioeconomic factors that have limited its use in plant resistance and integrated pest management. First, tolerance is difficult to identify and the mechanisms conferring it are mostly unknown. Second, the genetics of tolerance are mostly unknown. Third, several obstacles hinder the establishment of high-throughput phenotyping methods for large-scale screening of tolerance. Fourth, tolerance has received little attention from entomologists because, for most, primary interest, research training, and funding opportunities are in mechanisms which affect

27 pest biology, not plant biology. Fifth, the efforts of plant resistance are directed at controlling pest populations rather than managing plant stress. We conclude this paper by discussing future research and development activities. 


\section{INTRODUCTION}

Is tolerance the forgotten child of plant resistance? Its attributes are so appealing, yet it has received the least attention of the three types of plant resistance. As an insect pest management tactic, tolerance may be the consummate strategy (Pedigo \& Higley 1992). This is because a central tenet of integrated pest management (IPM) is that we tolerate some amount of pest injury. By making plants more tolerant of injury, we are achieving this important goal. Another goal is to use tactics that impose little selection pressure that will lead to pest resistance to those tactics. Contrary to antixenosis and antibiosis, tolerance does not affect insect biology or behavior (Smith 2005); therefore, pests cannot become resistant to tolerant plants. Clearly, the conceptual advantages of tolerance in plant resistance cannot be discounted.

We believe there are several reasons why tolerance has not been developed as successfully as antibiosis and antixenosis. First, tolerance is difficult to identify and the mechanisms conferring it are poorly understood. Second, the genetics of tolerance are mostly unknown. Third, several obstacles still hinder the establishment of high-throughput phenotyping methods for large-scale screening of tolerance. Fourth, tolerance has received little attention from entomologists because, for most, their primary interest, research training, and funding opportunities are in mechanisms which affect pest biology, not plant biology. Fifth, the efforts of plant resistance are still directed at controlling pest populations rather than managing plant stress. In this paper, we discuss tolerance and the factors that have limited its use in plant resistance and IPM.

\section{SURVEY METHODOLOGY}

Primary and secondary literature relevant to the topic of this paper was assessed using Web of Science (Clarivate Analytics) and Google Scholar. Key words such as "plant tolerance," 
55 "host plant resistance," "plant resistance," "insect resistance," "plant breeding," "pest

56 resistance," "antibiosis," and "antixenosis" were searched between 1 January and 31 May, 2017.

\section{DEFINITIONS AND CONCEPTS}

58 Before discussing the five factors above in detail, we first need to define tolerance. In this

59

60

61

62

63

64

65

66

67

68

69

70

71

72

73

74

75

76

instance, precisely defining terms is important because there continues to be considerable overlap in plant resistance definitions. At the outset, we recognize tolerance as distinctly different from the two other resistance types: antibiosis and antixenosis.

Antibiosis is a type of resistance that contains at least one plant characteristic that affects pest biology in a deleterious manner. Antixenosis is a type of resistance that contains at least one plant characteristic that directs a pest away from it. Tolerance is a type of resistance that causes the plant to compensate for pest injury to a degree exceeding non-tolerant plants (Kogan \& Ortman 1978; Painter 1951; Smith 2005). In an evolutionary context, tolerance is defined as the slope of the line describing the association between fitness and level of damage for a set of genetically related plants (Strauss \& Agrawal 1999). In agronomic situations, tolerant crop varieties are able to withstand injury and produce acceptable yields (Flinn et al. 2001; Qiu et al. 2011; Webster 1990; Webster et al. 1991). From an ecological perspective, tolerant plants can maintain fitness in response to pest injury (Núñez-Farfán et al. 2007; Rosenthal \& Kotanen 1994).

Both antibiosis and antixenosis involve a plant response and a pest response. However, in the case of tolerance only a plant response is involved. Therefore, there is a nonreciprocal process associated with tolerance (Smith 2005). This non-reciprocity has important ramifications when considering the use of tolerant cultivars in IPM programs. 
78

antibiosis and antixenosis) is not a mechanism of resistance (Smith 1997). There are numerous mechanisms conferring tolerance (Koch et al. 2016; Strauss \& Agrawal 1999; Tiffin 2000), just as there are numerous mechanisms for antibiosis and antixenosis (Du et al. 2009; War et al. 2012). Therefore, different and distinct mechanisms that enhance pest mortality collectively belong to the antibiosis resistance type.

What do we mean by stating that tolerant hosts can compensate for injury better than non-tolerant hosts? Plant response to biotic injury depends on four factors: the intensity of injury, the time of injury, the type of injury, the plant part injured, and interactions with environmental factors (Peterson \& Higley 2001). The intensity of injury is very important when considering the potential impact of the stressor on host yield or fitness. The relationship was described in the form of a damage curve by Tammes (1961), and has since been supported by substantial empirical evidence (Shelton et al. 1990).

Pedigo et al. (1986) defined portions of the damage curve more than two decades after its inception (Fig. 1). The damage curve can be used to present some of the basic aspects of tolerance. Although the initial portion of the damage curve is termed the tolerant region, there are actually four portions that can theoretically be expressed differentially by tolerant plants when compared with nontolerant plants. The damage curve can be altered by extending the initial zero slope of the damage curve; i.e., no damage per unit injury is expressed at higher levels of injury for tolerant plants than for nontolerant plants (Fig. 2a). Tolerant plants also may be able to affect the compensation area of the damage curve in two ways. First, because this area is curvilinear (with a negative decreasing slope), tolerant plants may express less damage per unit injury (Fig. 2b). Second, the slope is not altered, but the curvilinear portion is extended into 
100 higher levels of injury (Fig. 2c). The linear portion can also be affected by tolerant plants in two 101 ways. First, the constant, negative slope (constant damage per unit injury) may have a less 102 negative slope for tolerant plants (Fig. 2d). Second, the linear portion may be shorter. Therefore, 103 desensitization and inherent impunity would occur at a higher yield (Fig. 2e). The last portion,

104

105 106

overcompensation (increasing yield per unit injury), can be expressed by both tolerant plants and nontolerant plants; however, tolerant plants may express a higher yield increase per unit injury (Fig. 2f).

As we have suggested, the damage curve theoretically can be altered by plants expressing tolerance. The challenge remains to empirically identify empirically the portion or portions of the damage curve where tolerance is expressed by plants. In addition, simply because portions are identified in which tolerance is expressed does not mean those portions would be practical targets for plant breeding. The tolerance, overcompensation, and compensation portions (Fig. 2a,b,f) most likely would be the most practical, producer accepted, and economic targets for enhancing tolerance. Enhancing tolerance in the linearity, desensitization, and inherent impunity portions (Fig. 2c,d,e) most likely would not be acceptable to producers because economic yield loss would already be occurring in these portions, except perhaps for lower injury areas of the linearity portion.

Tolerance can also be expressed in the context of economic injury level (EIL) parameters. The relationship between damage per unit injury and the EIL typically takes the form of Fig. 3. Because a tolerant plant ultimately expresses less damage per unit injury, the EIL will be greater for most levels of injury. This relationship can also be expressed when considering pest population levels over time and the EIL (Fig. 3).

\section{CONSTRAINTS ON THE DEVELOPMENT AND USE OF TOLERANCE}




\section{Identifying tolerance and characterizing tolerance mechanisms is difficult}

124

125

126

127

128

129

130

131

132

133

134

135

136

137

138

139

140

141

142

143

144

145

A major factor contributing to the predominance of the use of antibiosis and antixenosis in plant resistance is sheer amenability. Antibiosis mechanisms often have been relatively easy to identify and breed for, mainly because they are, in many cases, determined by a single gene or major quantitative trait locus (QTL) and because their effects on herbivorous arthropods are readily apparent. We realize that the precise biochemical mechanisms for antibiosis in many systems are not known. For example, larval survival of the wheat stem sawfly, Cephus cinctus, is reduced by QTL on wheat chromosomes 2A, 3A, and 5B (Varella et al. 2015). Although specific mechanisms causing larval mortality have yet to be determined, this constraint has not hindered the identification of antibiosis and the ability to breed for wheat resistance to this pest.

Although antixenosis mechanisms are not as readily identifiable as antibiosis mechanisms, they still are more apparent than tolerance mechanisms. This is because antixenotic mechanisms usually involve plant morphological features that can be visually identified and because insect responses can be typically observed and measured. For example, the frego bract character in cotton and glandular trichomes in alfalfa (both of which discourage larval feeding and oviposition) are very apparent and efficacious (Jenkins \& Parrott 1971; Ranger \& Hower 2001). Even less visually apparent mechanisms such as surface waxes, tissue thickness, and chemical deterrents can be readily identified and assayed (Chamarthi et al. 2011; Jindal \& Dhaliwal 2011; Weaver et al. 2009).

In contrast to antixenosis and antibiosis, relatively little is known about tolerance.

Tolerance to arthropod injury has been identified in alfalfa, barley, rice, sorghum, maize, wheat, cotton, cowpea, okra, muskmelon, turnip, and tea (Velusamy \& Heinrichs 1986), northern red oak, Spanish cedar, Brassica rapa, tall fescue, and perennial ryegrass (Strauss \& Agrawal 1999), 
146 lentils, sugarcane, soybean, potato, switchgrass, and cacao (Koch et al. 2016), cassava, tomato,

147 and strawberry (Byrne et al. 1982; Gilbert et al. 1966; Schuster et al. 1980). In some of these

148 commodities, tolerance is a very important resistance attribute. For example, the resistance of

149 sorghum to greenbug, Schizaphis graminum, is dependent on the survival of seedlings in

150 response to feeding injury. This is clearly a tolerance response because resistant cultivars have

151 no effect on greenbug biology or behavior (Schuster \& Starks 1973). In barley, the identification

152 of Russian wheat aphid, Diuraphis noxia, populations virulent to resistance genes has recently

153 prompted the development of tolerant cultivars (e.g. "Sydney" and "Stoneham") in an attempt to

154 reduce selection pressure on the aphid population, thus increasing the durability of genotypes

155 (Haley et al. 2004; Marimuthu \& Smith 2012; Mornhinweg et al. 2009; Mornhinweg et al. 2012).

156 Despite its successful use in some crops, little is known about the mechanisms underlying 157 tolerance.

158 Tolerance is currently believed to be caused by six general physiological mechanisms: (i) 159 increased net photosynthetic rate after herbivory, (ii) high relative growth rates, (iii) increased 160 branching or tillering, (iv) pre-existing high levels of carbon storage in roots, (v) increased 161 resource allocation from root to shoot after damage (Strauss \& Agrawal 1999), and (vi) up162 regulation of detoxification mechanisms to counteract deleterious effects of herbivory (Koch et 163 al. 2016). Possible morphological features of tolerance include protected meristems, number of 164 meristems, and developmental plasticity (Rosenthal \& Kotanen 1994). At the molecular level, 165 only a few transcripts (e.g. SNF1-related kinases, peroxidases, and catalases) have been 166 identified as been involved in tolerance to herbivory through resource allocation (Schwachtje et 167 al. 2006) or reactive oxygen species (ROS) detoxification mechanisms (Ramm et al. 2013; Smith 168 et al. 2010). 
It is important to note that mechanisms that contribute to tolerance may vary with

170 herbivore specialization (e.g. specialists, generalists) (Agrawal \& Fishbein 2006; Delaney et al.

171 2008; Delaney et al. 2009; Delaney \& Higley 2006; Foyer et al. 2015), feeding guild (e.g.

172 chewing, sucking) (Zhou et al. 2015), the plant's symbiotic relationships (e.g. several milkweed

173 species show increased tolerance to herbivory when associated with arbuscular mycorrhizal

174 fungi) (Tao et al. 2016) and environmental conditions (Wise \& Abrahamson 2007). All of these

175 factors complicate the identification and characterization of tolerance mechanisms. Also, some

176 mechanisms are constitutively expressed while others are induced. Evaluation of germplasm

177 showing induced tolerance must be done in the presence of pest populations, which is often more

178 challenging due to seasonal variation in pest infestation at any given location.

179 Many crop varieties expressing tolerance have been discovered fortuitously.

180 Development of resistant cultivars usually has been the result of general screening for any

181 expression of resistance. For example, the development of the alfalfa cultivar "Team," which is

182 tolerant to alfalfa weevil, Hypera postica, injury, was the result of large-scale screenings of

183 germplasm, in which more than two million seedlings were exposed to weevil infestation in an

184 attempt to identify any resistance. After 10 years of breeding, "Team" was released in 1970. The

185 cultivar is believed to express all three resistance types, but tolerance seems to be the dominant

186 resistance factor (Barnes et al. 1970). It should be noted that the goal of the researchers was not

187 to characterize mechanisms, but rather to produce a resistant variety. Large scale screenings

188 focusing exclusively on plant tolerance have also been successful (Dunn et al. 2011).

189 The genetics of tolerance are mostly unknown

The ability to predict phenotypic characteristics based on plant genotype is key to 
192 to germplasm screening and selection. Nevertheless, understanding the genetics of plant

193 tolerance to herbivory, as with any other trait, requires both the capability to detect polymorphic

194 alleles and the recombination or segregation of these alleles.

195 To meet these requirements, large breeding populations need to be developed and

196 screened. Lack of knowledge of the mechanisms underlying tolerance hinders the ability to

197 precisely phenotype plants and interferes with the capacity of detecting polymorphisms. Despite

198 the challenges, genetic variation in tolerance to herbivory has been demonstrated in crop and

199 non-crop species (Marimuthu \& Smith 2012; Punnuri et al. 2013; Shen \& Bach 1997). Similar to

200 antibiosis and antixenosis, tolerance seems to be mostly controlled by multiple loci and their

201 interactions. Though QTL associated with tolerance to herbivory have been identified, to our

202 knowledge, no gene has been cloned. Thus, further research should aim to enhance the genetic

203 resolution of target QTL, which ultimately may result in the identification and cloning of causal

204 genes.

205 Establishing high-throughput screening methods for large-scale phenotyping of tolerance is 206 difficult

207 One of the bottlenecks of breeding for insect tolerance is the difficulty in identifying

208 diagnostic traits that can be easily, precisely, and consistently quantified under natural and/or

209 imposed insect pressure. Screening methods that are laborious or time-consuming might be

210 adequate for research purposes, but are for the most part not useful for screening the large

211 number of lines regularly phenotyped in plant breeding programs.

212 For example, wheat tolerance to the bird cherry-oat aphid, Rhopalosiphum padi, can be

213 assessed using a diverse set of methods that target a variety of plant traits (e.g. gain yield,

214 thousand kernel mass, biomass ratios, and development of roots and shoots) (Dunn et al. 2011; 
215 Lamb \& MacKay 1995; Papp \& Mesterházy 1993). However, not all methods allow for the

216 evaluation of thousands of plants in a timely manner (Dunn et al. 2011). Thus, the establishment

217 of high-throughput phenotyping methods that allow for the precise characterization of a large

218 number of lines will greatly contribute for the development of tolerant crop plants. Challenges

219 associated with implementing high-throughput phenotyping for plant breeding programs are

220 associated with costs of equipment, facilities, and software licenses (required for data analysis),

221 lack of personnel trained for manipulation of large data sets, and lack of standards for

222 experimental design and data analysis (Goggin et al. 2015).

223 Entomologists lack substantial training in plant biology

Because entomologists have been the primary participants in research on plant resistance to insects, entomocentric views have prevailed. Consequently, instead of concentrating on plant responses to insect-induced injury, entomologists have often used the plant to deliver a control tactic. This strategy reflects an inherent disadvantage in research training specialization (overspecialization?) of contemporary scientists (Jacobs \& Frickel 2009; Rhoten 2004; Welter 1989). Very few entomologists have had formal training in aspects of plant biology, such as photosynthesis, metabolism, anatomy, and water relations. Entomologists trained to consider the plant in insect-plant interactions potentially would improve research and development of tolerant cultivars. Additionally, interdisciplinary research teams may be able to develop tolerant cultivars. However, interdisciplinary research incorporating aspects of pest biology, plant physiology, and agronomy is still in its infancy (Peterson 2001; Peterson \& Higley 2001).

Plant resistance efforts are targeted toward the control of pest populations 
238 tactic of insecticide use common in the 1950s and early 1960s. Through antixenosis, and

239 especially antibiosis mechanisms, resistant cultivars essentially are suppressing insect

240 populations. Unlike insecticide use, the adverse environmental impacts of using resistant

241 cultivars are quite low. In this respect, resistant cultivars satisfy one objective of IPM:

242 minimizing detrimental environmental effects. However, cultivars with antibiotic mechanisms

243 place selection pressure on insect populations, potentially encouraging the development of

244 resistance. Although, resistant cultivars may represent a more desirable control tactic, they do not

245 necessarily represent a truly sustainable pest management practice. New approaches for

246 incorporating resistance in plants also will not be sustainable. For example, plants that are

247 engineered to produce the Bacillus thuringiensis $(\mathrm{Bt})$ toxin have selected for resistance (even

248 when pest populations were not economic) (Tabashnik et al. 2008).

249 The issue of control versus management in IPM is a critical factor when attempting to

250 understand why tolerance is not as prominent in plant resistance. The terms "control" and

251 "management" as they relate to pest management have been discussed (Higley \& Pedigo 1993;

252 Higley \& Pedigo 1996; Menalled et al. 2016; Pedigo \& Higley 1996; Pedigo \& Rice 2009).

253 Briefly, "control" implies a program focused on the pests themselves, and, in particular killing

254 pests. Therefore, this often results in strong selection pressure for resistance. The focus on killing

255 pests includes the highly efficacious antibiotic tactic represented by Bt crops. In contrast,

256 "management" implies a program focused on the "judicious use of means to accomplish a

257 desired end" (Pedigo \& Higley 1996). Tolerance, then, as a type of plant resistance, clearly fits

258 well with management.

259 Other biological factors 
261 because tolerance has been so poorly studied and understood, we do not know if or how much

262 specific interactions with the environment (such as drought or heat stress) will render the tolerant

263 variety completely susceptible to pest injury. This is especially relevant in the face of climate

264 change and the increase in drought-prone areas. In non-crop species for instance, drought has

265 been shown to limit a plant's ability to tolerate herbivory (Atala \& Gianoli 2009; Gonzáles et al.

266 2008). But even closely related species of plants may respond differently to herbivory under

267 drought conditions (Shibel \& Heard 2016). Thus, the impact of environment on the plant's

268 ability to tolerate insect herbivory might have to be assessed for each crop species and/or variety.

269 In several crop systems, some arthropod species move from one crop species to another

270 during their life cycle. For example, in North Carolina the corn earworm, Helicoverpa zea, may

271 injure corn, tobacco, wild hosts, soybean, and cotton. Having just one crop species in an area

272 tolerant to corn earworm injury may result in unacceptable populations for the other crop

273 species.

\section{Socioeconomic factors}

275 In the U.S., growers attempt to control pests to avoid risk as much as, if not more, than to optimize yields (Higley 2006). Understandably, then, growers may be uncomfortable with a

277 large number of pests feeding on their tolerant cultivar. In this case, the cultivar may be able to 278 tolerate the injury, but the grower cannot. The attitude that the "only good bug is a dead bug" is 279 undoubtedly alive and well in modern farming systems. Additionally, private companies may not 280 embrace tolerant cultivars because they do not want their customers to doubt that their varieties 281 are indeed resistant. Therefore, education about tolerance and tolerant cultivars must be a priority 282 if this resistance strategy is to be successful. 

identified several rice lines that are tolerant to rice weevil, Sitophilus oryzae, injury. However, crops and must be addressed by researchers. Another major limitation is that tolerant crops may be more vulnerable to cosmetic damage than crops displaying other types of resistance. tolerance in some crop species.

291

292

293

294

\section{CONCLUSIONS AND RECOMMENDATIONS}

Although antixenosis and antibiosis may lessen or negate the need for pesticides applied to the crop, they can produce selective pressures on insect populations that are similar to pesticides. The management tactic may be more environmentally acceptable and therefore may be more popular with policy makers and the public, but if sufficient selective pressure is placed on the pest population the tactic is not sustainable in the long term (Kennedy et al. 1987; Tolmay et al. 2007). Tolerance, as a resistance mechanism, is very appealing because it is a sustainable tactic (Kennedy et al. 1987; Pedigo 1995; Pedigo \& Rice 2009; Rausher 2001). By not placing selective pressure on insect populations, it essentially factors the pest out of the equation. Additionally, EILs for tolerant varieties would be substantially higher than for susceptible varieties. Therefore, reduced pesticide inputs would result. Because of these factors, tolerance is a more stabilizing management strategy for pests.

Velusamy and Heinrichs (1986) list three factors they believe are responsible for the lack of attention to tolerance. They include: a lack of suitable techniques to identify and incorporate tolerance into crops; the ability of tolerant cultivars to serve as reservoirs for insect vectors of 
306 viruses; and, the lack of basic information on the inheritance of tolerance. We believe they have

307 identified three factors that potentially constrain the development of tolerance. However, we

308 believe our factors are more encompassing, reflecting the biological, economic, and social

309 constraints on tolerance development. For example, the lack of suitable techniques to identify

310 tolerance is really a reflection of the lack of understanding about basic physiological mechanisms

311 underlying tolerance.

312 Before substantial work on tolerance development can occur, we must conduct basic

313 research on the physiological and biochemical mechanisms of tolerance. This must involve

314 interdisciplinary research between plant scientists and entomologists. Beyond an

315 interdisciplinary focus, it is important that there is awareness from applied researchers about

316 research and findings from fundamental researchers and vice-versa. There are longstanding

317 issues of lack of communication between biologists, ecologists, and agricultural scientists

318 (Higley et al. 1993) and this must be addressed before tolerance can be appreciably advanced.

319 More generally, research on the physiological responses of plants to arthropod injury

320 (irrespective of tolerance) must progress beyond what is currently known. Higley et al. (1993)

321 argued that a focus on plant physiology provides a common language for characterizing plant

322 stress and is essential for integrating understanding of stress. Peterson and Higley (1993) and

323 Peterson (2001) discuss approaches for synthesizing plant responses to arthropod injury.

324 Based on the factors we have discussed above, we believe the development and use of

325 tolerance in plant resistance to arthropods can be hastened by achieving the following goals: (1)

326 research characterizing the physiological mechanisms underlying tolerance; (2) research

327 determining the physiological responses of plants to arthropod injury; (3) encouragement of

328 interdisciplinary research and communication among entomologists, plant scientists, ecologists, 
329

330

331

332

333

334

335

336

337

338

339

340

341

342

343

344

345

346

347

348

349

350

351

352

353

354

355

356

357

358

359

360

361

362

363

364

365

366

367

368

369

and molecular biologists; and, (4) progression of IPM theory to a true paradigm for managing

plant stress. Ultimately, to understand the conceptual importance of tolerance to plant resistance,

the importance of tolerance to IPM must be appreciated.

\section{References}

Agrawal AA, and Fishbein M. 2006. Plant defense syndromes. Ecology 87:S132-S149.

Atala C, and Gianoli E. 2009. Effect of water availability on tolerance of leaf damage in tall morning glory, Ipomoea purpurea. Acta Eocologica 35:236-424.

Barnes DK, Hanson CH, Ratcliffe RH, Busbice TH, Schillinger JA, Buss GR, Campbell WV, Hemken RW, and Blickenstaff CC. 1970. The development and performance of Team alfalfa. Washington, DC: U.S. Department of Agriculture Bulletin ARS 34-115.

Byrne DH, Guerrero JM, Bellotti AC, and Gracen VE. 1982. Yield and plant-growth responses of Mononychellus mite resistant and susceptible cassava cultivars under protected vs infested conditions. Crop Science 22:486-490.

Chamarthi S, Sharma H, Vijay P, and Narasu M. 2011. Leaf surface chemistry of sorghum seedlings influencing expression of resistance to sorghum shoot fly, Atherigona soccata. Journal of Plant Biochemistry and Biotechnology 20:211-216.

Delaney KJ, Haile FJ, Peterson RKD, and Higley LG. 2008. Impairment of leaf photosynthesis after insect herbivory or mechanical injury on common milkweed, Asclepias syriaca. Environmental Entomology 37:1332-1343.

Delaney KJ, Haile FJ, Peterson RKD, and Higley LG. 2009. Seasonal patterns of leaf photosynthesis after insect herbivory on common milkweed, Asclepias syriaca: Reflection of a physiological cost of reproduction, not defense? American Midland Naturalist 162:224-238.

Delaney KJ, and Higley LG. 2006. An insect countermeasure impacts plant physiology: midrib vein cutting, defoliation and leaf photosynthesis. Plant, Cell and Environment 29:12451258.

Du B, Zhang W, Liu B, Hu J, Wei Z, Shi Z, He R, Zhu L, Chen R, Han B, and He G. 2009. Identification and characterization of Bph14, a gene conferring resistance to brown planthopper in rice. Proceedings of the National Academy of Sciences 106:22163-22168.

Dunn B, Porter D, Baker C, and Carver B. 2011. Screening USDA-ARS wheat germplasm for bird cherry-oat aphid tolerance. Journal of Crop Improvement 25:176-182.

Flinn M, Smith M, Reese J, and Gill B. 2001. Categories of resistance to greenbug (Homoptera: Aphididae) biotype I in Agilops tauschii germplasm. Journal of Economic Entomology 94:558-563.

Foyer CH, Verrall SR, and Hancock RD. 2015. Systematic analysis of phloem-feeding insectinduced transcriptional reprogramming in Arabidopsis highlights common features and reveals distinct responses to specialist and generalist insects. Journal of Experimental Botany 66:495-512.

Gilbert JC, Chinn JT, and Tanaka JS. 1966. Spider mite tolerance in multiple disease resistant tomatoes. Proceedings of the American Society for Horticultural Science 89:559-562. 
Goggin F, Lorence A, and Topp C. 2015. Applying high-throughput phenotyping to plant-insect interactions: picturing more resistant crops. Current Opinion in Insect Science 9:69-76.

Gonzáles W, Suárez L, and Molina-Montenegro M. 2008. Water availability limits tolerance of apical damage in the Chilean tarweed Madia sativa. Acta Oecologica 34:104-110.

Haley S, Quick J, Johnson J, Peairs F, Stromberger J, and Clayshulte S. 2004. Registration of 'Anchor' wheat. Crop Science 44:1025-1026.

Higley LG. 2006. The devil and Leon Higley: an IPM story. In: Gray M, editor. Illinois Crop Protection Technology Conference. Urbana, Illinois: University of Illinois Extension. p 132-134.

Higley LG, Browde JA, and Higley PM. 1993. Moving towards new understandings of biotic stress and stress interactions. In: Buxton DR, Shibles R, Forsberg RA, Blad BL, Asay KH, Paulsen GM, and Wilson RF, eds. International Crop Science I. Madison, Wisconsin: Crop Science Society of America, 749-754.

Higley LG, and Pedigo LP. 1993. Economic Injury Level concepts and their use in sustaining environmental quality. Agriculture, Ecosystems and Environment 46:233-243.

Higley LG, and Pedigo LP. 1996. Pest science at a crossroads. In: Higley L, and Pedigo L, eds. Economic Thresholds for Integrated Pest Management. Lincoln, Nebraska: University of Nebraska Press.

Jacobs J, and Frickel S. 2009. Interdisciplinarity: a critical assessment. Annual Review of Sociology 35:43-65.

Jenkins J, and Parrott W. 1971. Effectiveness of frego bract as a boll weevil resistance character in cotton. Crop Science 11:739-743.

Jindal V, and Dhaliwal G. 2011. Mechanisms of resistance in cotton to whitefly (Bemisia tabaci): antixenosis. Phytoparasitica 39:129-136.

Kennedy GG, Gould F, Deponti OMB, and Stinner RE. 1987. Ecological, agricultural, genetic, and commercial considerations in the deployment of insect-resistant germplasm. Environmental Entomology 16:327-338.

Koch K, Chapman K, Louis J, Heng-Moss T, and Sarath G. 2016. Plant tolerance: a unique approach to control hemipteran pests. Frontiers in Plant Science 7:1363.

Kogan M, and Ortman E. 1978. Antixenosis: a new term proposed to define Painter's "nonpreference" modality of resistance. Bulletin of the Entomological Society of America 24:175-176.

Lamb R, and MacKay P. 1995. Tolerance of antibiotic and susceptible cereal seedlings to the aphids Metopolophium dirhodum and Rhopalosiphum padi. Annals of Applied Biology 127:573-583.

Marimuthu M, and Smith M. 2012. Barley tolerance of Russian wheat aphid (Hemiptera: Aphididae) biotype 2 herbivory involves expression of defense response and developmental genes. Plant Signalling and Behavior 7:1-10.

Menalled FD, Peterson RKD, Smith RG, Curran WS, Paez DJ, and Maxwell BD. 2016. The ecoevolutionary imperative: revisiting weed management in the midst of an herbicide resistance crisis. Sustainability 8.

Mornhinweg D, Bregitzae P, Porter D, Peairs F, Baltensperger D, Hein G, Randolph T, Koch M, and Walker T. 2009. Registration of 'Sidney' spring feed barley resistant to Russian wheat aphid. Journal of Plant Registrations 3. 
414

415

416

417

418

419

420

421

422

423

424

425

426

427

428

429

430

431

432

433

434

435

436

437

438

439

440

441

442

443

444

445

446

447

448

449

450

451

452

453

454

455

456

457
Mornhinweg D, Bregitzae P, Porter D, Peairs F, Baltensperger D, Hein G, Randolph T, Koch M, and Walker T. 2012. Registration of 'Stoneham' spring feed barley resistant to Russian wheat aphid. Journal of Plant Registrations 6:1-5.

Nguessan FK, and Quisenberry SS. 1994. Screening selected rice lines for resistance to the rice water weevil (Coleoptera: Curculionidae). Environmental Entomology 23:665-675.

Núñez-Farfán J, Fornoni J, and Valverde P. 2007. The evolution of resistance and tolerance to herbivores. Review of Ecology, Evolution, and Systematics 38:541-566.

Painter R. 1951. Insect resistance in crop plants. Lawrence, Kansas: University of Kansas Press.

Papp M, and Mesterházy Á. 1993. Resistance to bird cherry-oat aphid (Rhopalosiphum padi L.) in winter wheat varieties. Journal of Economic Entomology 89:1649-1657.

Pedigo LP. 1995. Closing the gap between IPM theory and practice. Journal of Agricultural Entomology 12:171-181.

Pedigo LP, and Higley LG. 1992. The economic injury level concept and environmental quality. American Entomologist 38:12-21.

Pedigo LP, and Higley LG. 1996. Introduction to pest management and thresholds. In: Higley L, and Pedigo L, eds. Economic Thresholds for Integrated Pest Management. Lincoln, Nebraska: University of Nebraska Press.

Pedigo LP, Hutchins SH, and Higley LG. 1986. Economic injury levels in theory and practice. Ann Rev Entomol 31:341-368.

Pedigo LP, and Rice ME. 2009. Entomology and Pest Management. Long Grove, Illinois: Waveland Press.

Peterson RKD. 2001. Photosynthesis, yield loss, and injury guilds. In: Peterson RKD, and Higley LG, eds. Biotic Stress and Yield Loss. New York: CRC press, 83-97.

Peterson RKD, and Higley LG. 1993. Arthropod injury and plant gas exchange: Current understandings and approaches for synthesis. Trends in Agril Sci 1:93-100.

Peterson RKD, and Higley LG. 2001. Illuminating the black box: the relationship beween injury and yield. In: Peterson RKD, and Higley LG, eds. Biotic Stress and Yield Loass. New York: CRC Press, 1-12.

Punnuri S, Huang Y, Steets J, and Wu Y. 2013. Developing new markers and QTL mapping for greenbug resistance in sorghum [Sorghum bicolor (L.) Moench]. Euphytica 191:191-203.

Qiu Y, Guo J, Jing S, Tang M, Zhu L, and He G. 2011. Identification of antibiosis and tolerance in rice varieties carrying brown planthopper resistance genes. Entomologia Experimentalis et Applicata 141:224-231.

Ramm C, Saathoff A, Donze T, Heng-Moss T, Baxendale F, Twigg P, Baird L, and Amundsen K. 2013. Expression profiling of four defense-related buffalograss transcripts in response to chinch bug (Hemiptera: Blissidae) feeding. Journal of Economic Entomology 106:2568-2576.

Ranger C, and Hower A. 2001. Role of the glandular trichomes in resistance of perennial alfalfa to the potato leafhopper (Homoptera: Cicadellidae). Journal of Economic Entomology 94:950-957.

Rausher M. 2001. Co-evolution and plant resistance to natural enemies. Nature 411:857-864.

Rhoten D. 2004. Interdisciplinary research: trend or transition. Items Issues 51:145-148.

Rosenthal J, and Kotanen P. 1994. Terrestrial plant tolerance to herbivory. Trends in Ecology and Evolution 9:145-148. 
458

459

460

461

462

463

464

465

466

467

468

469

470

471

472

473

474

475

476

477

478

479

480

481

482

483

484

485

486

487

488

489

490

491

492

493

494

495

496

497

498

499

500

501

502

503

Schuster DJ, Price JF, Martin FG, Howard CM, and Albregts EE. 1980. Tolerance of strawberry cultivars to twospotted spider mites Acari, Tetranychidae in Florida. Journal of Economic Entomology 73:52-54.

Schuster DJ, and Starks KJ. 1973. Greenbugs (Homoptera: Aphididae): Components of hostplant resistance in sorghum. Journal of Economic Entomology 66:1131-1134.

Schwachtje J, Minchin P, Jaunke S, van Dongen A, Schittko U, and Baldwin I. 2006. SNF1related kinases allow plants to tolerate herbivory by allocating carbon to roots. Proceedings of the National Academy of Sciences 103:12935-12940.

Shelton A, Hoy C, and Baker P. 1990. Response of cabbage head weight to simulated Lepidoptera defoliation. Entomologia Experimentalis et Applicata 54:181-187.

Shen C, and Bach C. 1997. Genetic variation in resistance and tolerance to insect herbivory in Salix cordata. Ecological Entomology 22:335-342.

Shibel Z, and Heard S. 2016. Synergistic and additive effects of drought stress and simulated herbivory on two goldenrods, Solidago altissima and S. gigantean. Botany 94:635-642.

Smith C. 1997. An overview of mechanisms and bases of insect resistance in maize. In: Mihm J, editor. Insect Resistant Maize: Recent Advances and Utilization Proceedings of an International Symposium held at the International Maize and Wheat Improvement Center (CIMMYT), 27 Nov - 3 Dec, 1994. Mexico. p 1-12.

Smith C. 2005. Plant resistance to arthropods: molecular and conventional approaches. New York: Springer.

Smith C, Liu X, Wang L, Liu X, Chen M, Starkey S, and Bai J. 2010. Aphid feeding activates expression of a transcriptome of oxylipin-based defense signals in wheat involved in resistance to herbivory. Journal of Chemical Ecology 36.

Strauss S, and Agrawal A. 1999. The ecology and evolution of plant tolerance to herbivory. Trends in Ecology and Evolution 14:179-185.

Tabashnik B, Gassmann A, Crowder D, and Carrière Y. 2008. Insect resistance to Bt crops: evidence versus theory. Nature Biotechnology 26:199-202.

Tammes PML. 1961. Studies of yield losses II. Injury as a limiting factor of yield. Tijdschr Planteziekten 67:257-263.

Tao L, Ahmad A, Roode J, and Hunter M. 2016. Arbuscular mycorrhizal fungi affect plant tolerance and chemical defences to herbivory through different mechanisms. Journal of Ecology 104:561-571.

Tiffin P. 2000. Mechanisms of tolerance to herbivore damage: what do we know? Evolutionary Ecology 14:523-536.

Tolmay V, Lindeque R, and Prinsloo G. 2007. Preliminary evidence of a resistance-breaking biotype of the Russian wheat aphid, Diuraphis noxia (Kurdjumov) (Homoptera: Aphididae) in South Africa. African Entomology 15:228-230.

Varella A, Weaver D, Sherman J, Black N, Heo H-Y, Kalous J, Chao J, Hofland M, Martin J, Kephart K, and Talbert L. 2015. Association analysis of stem solidness and wheat stem sawfly resistance in a panel of North American spring wheat germplasm. Crop Science 55:2046-2055.

Velusamy R, and Heinrichs E. 1986. Tolerance in crop plants to insect pests. Insect Science and Application 7:689-696.

War A, Paulraj M, Ahmad T, Buhroo A, Hussain B, Ignacimuthu S, and Sharma H. 2012. Mechanisms of plant defense against insect herbivores. Plant Signaling and Behavior 7:1306-1320. 
504 Weaver D, Buteler M, Hofland M, Runyon J, Nansen C, Talbert L, Lamb P, and Carlson G.

505

506

507

508

509

510

511

512

513

514

515

516

517

518

519

520 2009. Cultivar preferences of ovipositing wheat stem sawflies as influenced by the amount of volatile attractant. Journal of Economic Entomology 102:1009-1017.

Webster J. 1990. Yellow sugarcane aphid (Homoptera: Aphididae): detection and mechanism of resistance among Ethiopian sorghum lines. Journal of Economic Entomology 83:10531057.

Webster J, Baker C, and Porter D. 1991. Detection and mechanisms of Russian wheat aphid (Homoptera: Aphididae) resistance in barley. Journal of Economic Entomology 84:669673.

Welter SC. 1989. Arthropod impact on plant gas exchange. In: Bernays EA, ed. Plant-Insect Interactions. Boca Raton: CRC, 135-150.

Wise M, and Abrahamson W. 2007. Effects of resource availability on tolerance of herbivory: a review and assessment of three opposing models. American Naturalist 169:443-454.

Zhou S, Lou Y, Tzin V, and Jander G. 2015. Alteration of plant primary metabolism in response to insect herbivory. Plant Physiology 169:1488-1498. 
Figure 1

The damage curve relating intensity of injury to yield.

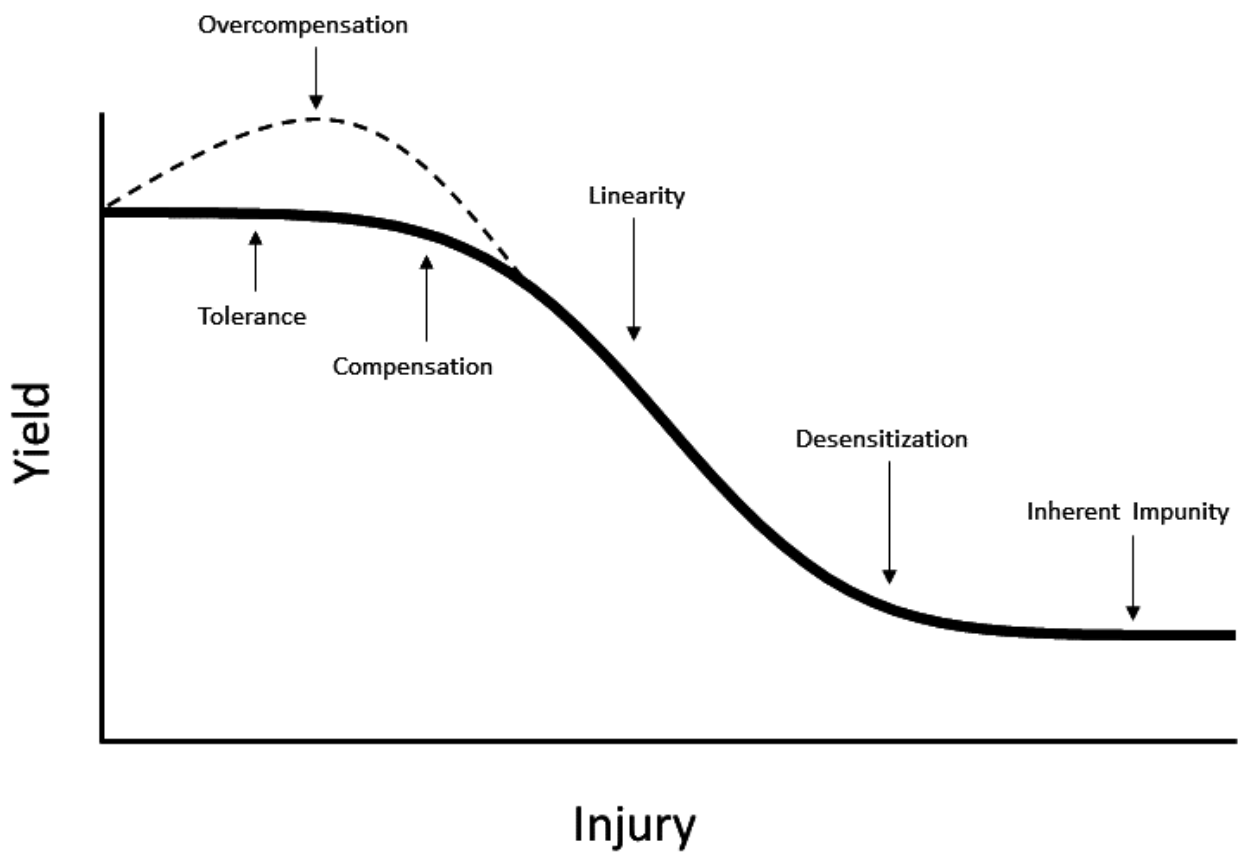




\section{Figure 2}

The damage curve showing different portions where tolerance can be expressed.

a) shows extending the initial zero slope of the damage curve, i.e., no damage per unit injury may be expressed at higher levels of injury for tolerant plants than for nontolerant plants; $b$ ) shows that because this area is curvilinear (with a negative decreasing slope), tolerant plants may express less damage per unit injury; c) shows that the curvilinear portion may be extended into higher levels of injury; d) shows that the constant, negative slope (constant damage per unit injury) may have a less negative slope for tolerant plants; e) shows that the linear portion may be shorter; e) shows that desensitization and inherent impunity may occur at a higher yield; f) shows that overcompensation (increasing yield per unit injury), may be expressed by both tolerant plants and nontolerant plants, but tolerant plants may express a higher yield increase per unit injury. 

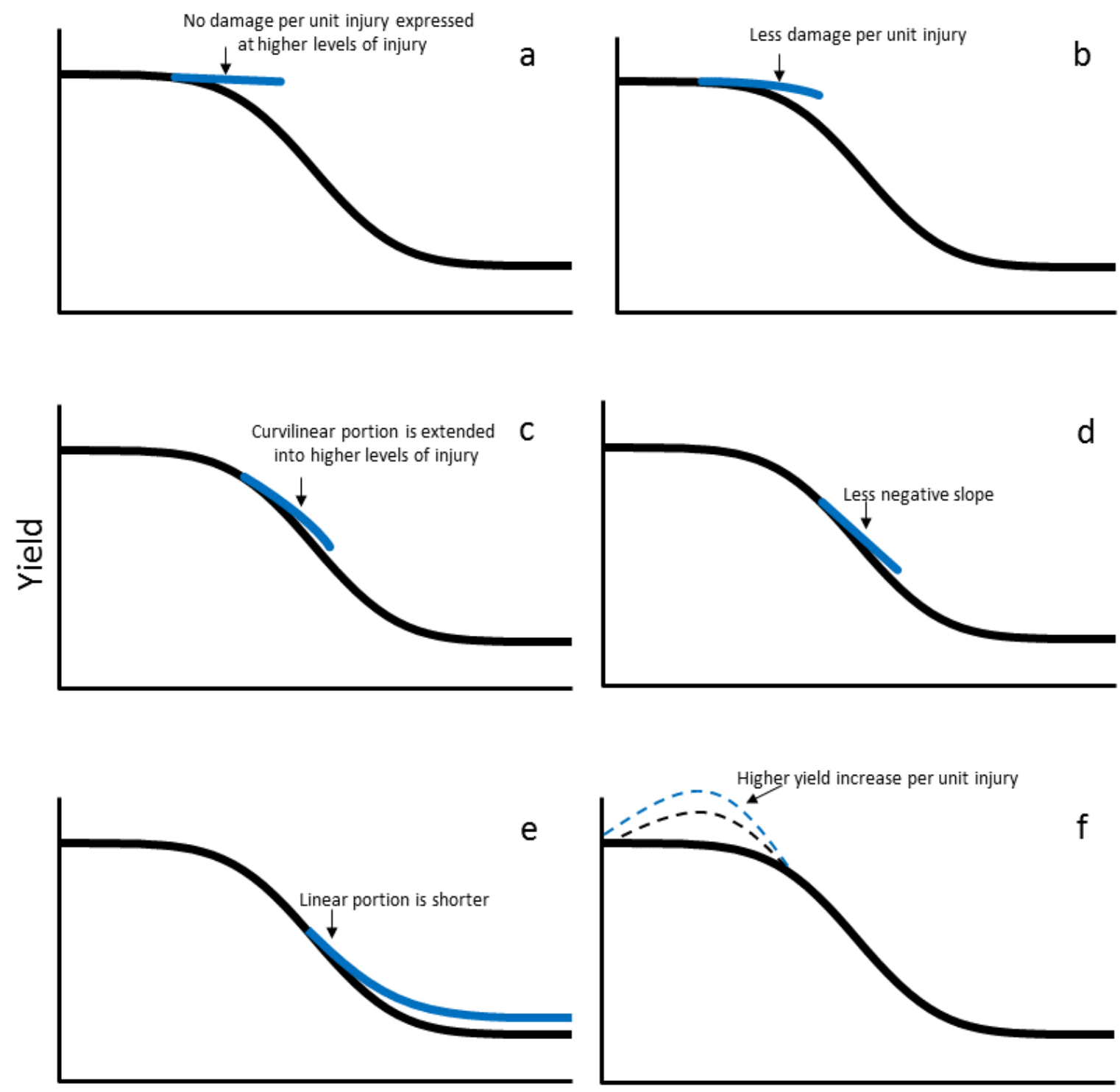

Injury 
Figure 3

The relationship between injury (often expressed as number of insects), time, and the economic injury level with and without tolerance.

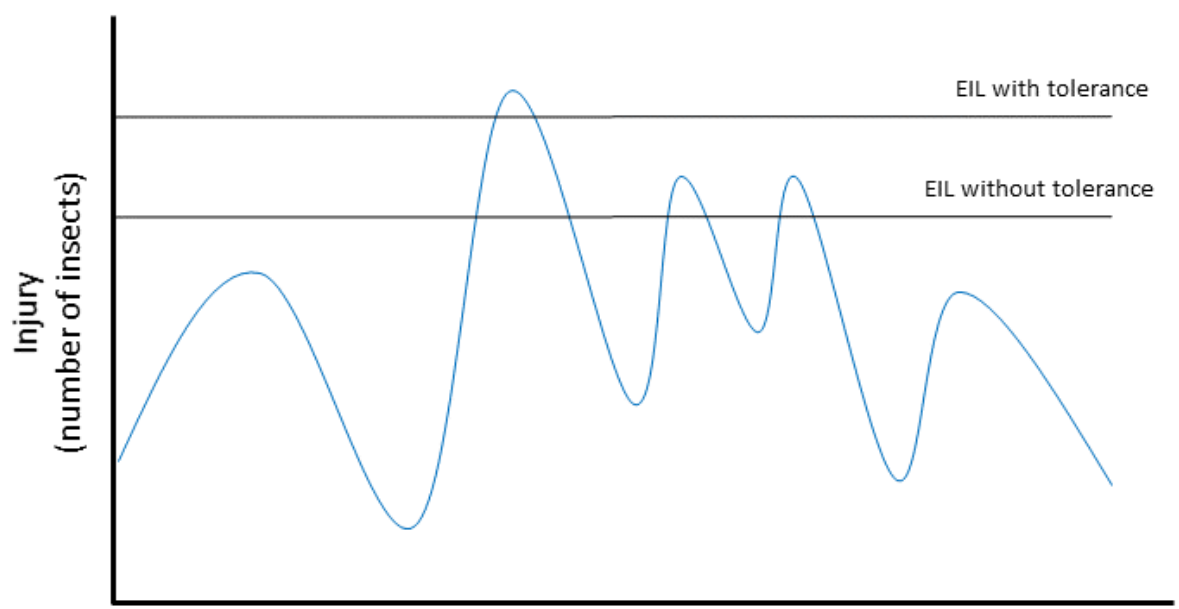

Time 